\title{
A Possible New Solstitial Sightline in the Stonehenge Landscape
}

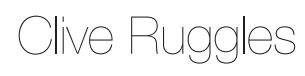

University of Leicester

rug@le.ac.uk

\section{Amanda Chadburn}

Historic England

Amanda.Chadburn@HistoricEngland.org.uk

Matt Leivers

Wessex Archaeology

m.leivers@wessexarch.co.uk

\section{Andrew Smith}

University of Adelaide

agksmith@internode.on.net

Abstract: The landscape around Stonehenge contains a number of major Early Neolithic monuments dating to the fourth millennium BC, including the Stonehenge Cursus, the Lesser Cursus, Robin Hood's Ball causewayed enclosure and several long barrows. A previously unsuspected Early Neolithic causewayed enclosure whose northeast rim was uncovered in 2016 on the slopes of Lark Hill, just to the north of the World Heritage Site boundary, represented a major new discovery. About a millennium after the construction of the Lark Hill Enclosure, a line of at least six timber posts was erected crossing from the interior to the exterior of the old enclosure, just to one side of a wide entrance. The line is slightly curved but the last three posts in the line face directly out towards the position of June solstice sunrise. While several short and longer rows of posts are now known to have been built in this vicinity both during the Later Neolithic and at later times, there are several reasons for believing this solstitial alignment to have been intentional and meaningful. It may even have represented the "monumentalisation" of an earlier broadly solstitial alignment of natural features, as has been suggested at Stonehenge itself.

Keywords: alignment; causewayed enclosure; Lark Hill; Neolithic; solstice; Stonehenge 


\section{Introduction}

Excavations undertaken in 2016-2017 by Wessex Archaeology at the garrison town of Larkhill to the northeast of Stonehenge, prior to the construction of a new Ministry of Defence housing development, revealed part of the outer ditch-and-bank circuit of a previously unsuspected Early Neolithic (EN) causewayed enclosure (Leivers 2017), now known as the Lark Hill Enclosure. A string of five excavated ditch segments (Figure 1B) evidently formed its northeastern extremity, and cattle bone found within one of them has shown the date of construction to be between 3780 and 3650 (cal) BC. The causeway separating the southeasternmost two segments is unusually wide $(14.5 \mathrm{~m})$, and the ditch terminal on its southeastern side is displaced outwards, suggesting that this may have been an entrance feature (Leivers 2021). If so, then it would have faced northeastwards down a dry valley leading to a bend in the River Avon.

Over a millennium later, at about the time the sarsen stones were being erected at Stonehenge, a line of at least six timber posts was erected in a southwest to northeast direction, crossing the enclosure boundary just to the southeast of the entrance (Figures $1 \mathrm{C} ; 2$ ). Posthole P1 (the southwesternmost) was found within the enclosure, P2 was close to the outer edge of the outward-flaring ditch (which by this time was partly infilled) and the remaining four P3-P6 lead out beyond. Cattle bone found in P2 has been dated to 2480-2290 (cal) BC (SUERC-70508, $3911 \pm 29$ BP). The line of postholes stretches for approximately $30 \mathrm{~m}$ and may have continued to the southwest, but definitely did not continue further to the northeast, where the relevant area was extensively excavated. The approximately solstitial alignment of the posts was immediately noted as something of potential signficance given the solstitial sightlines that are known to have been monumentalised at around this time at Stonehenge, Woodhenge and Durrington Walls Henge (Ruggles 2006; Chadburn and Ruggles 2017).

The postholes were circular or subcircular, with steep straight or slightly concave sides, and flat or concave bases. Only P6 was different in profile, showing a possible insertion ramp on its southern side, where a large timber could have been levered into position. The postholes at Woodhenge were similar in shape, and some postholes there also had insertion ramps, particularly Rings $B$ and C, although every ring had an example of such a ramp (Cunnington 1929, plate 4).

These features at Lark Hill have been identified as postholes rather than pits for a number of reasons, and despite the fact that there was no evidence of postpipes. One reason for this identification is that the holes contained chalk packing material which originally would have been placed around an upright to hold it in place, and the final position of this material, slumping towards the base of the features and creating nearhorizontal deposits, was indicative of posts having been removed. The shapes of the holes are also more like postholes than pits, and the insertion ramp at P6 is further evidence of a large post being pulled into place. As there was no evidence of postpipes, this suggests that timbers were withdrawn rather than burnt or allowed to decay in situ. This also means that it is difficult to measure the precise original alignment, although the centre points of the postholes give a very good indication. 

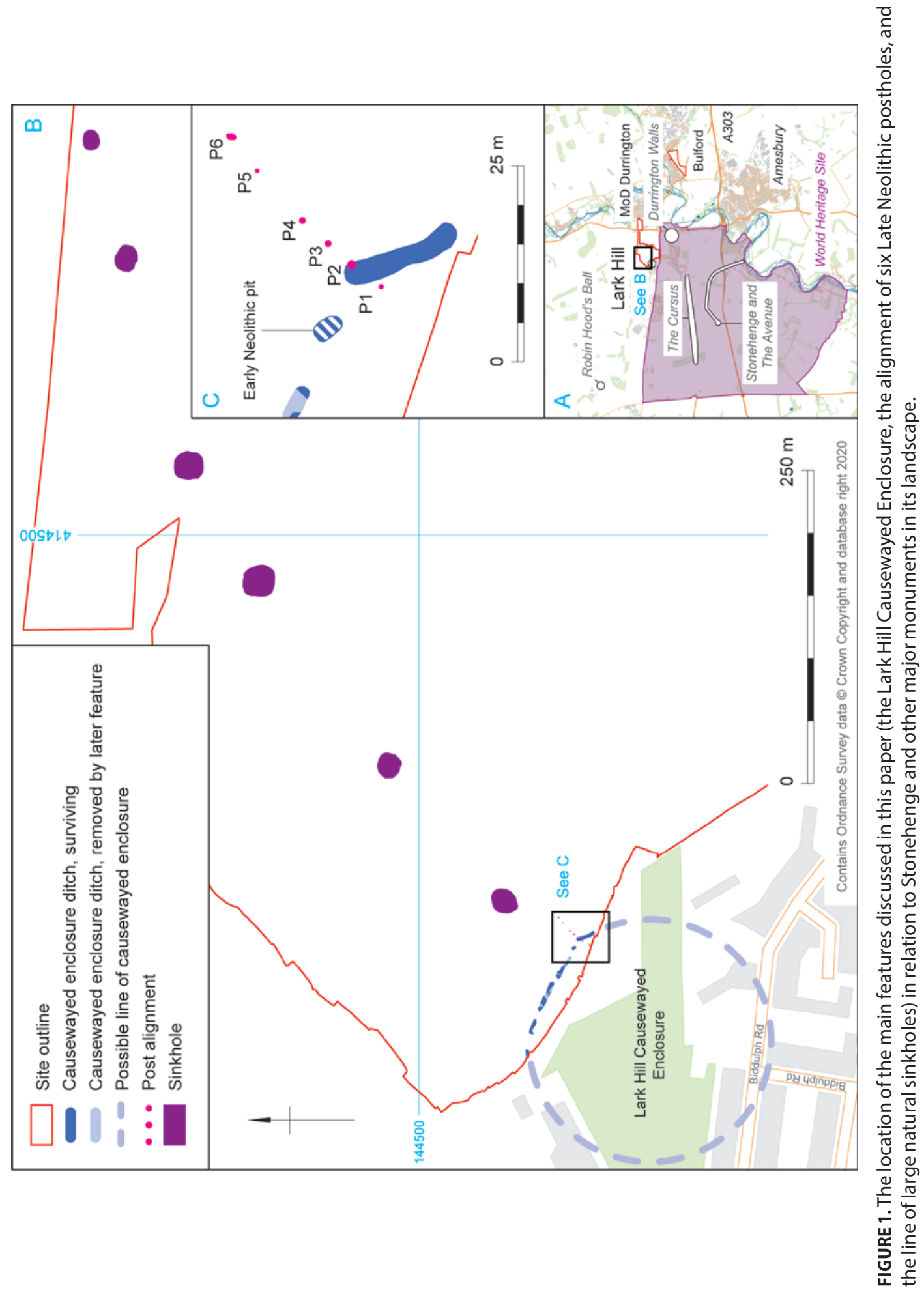


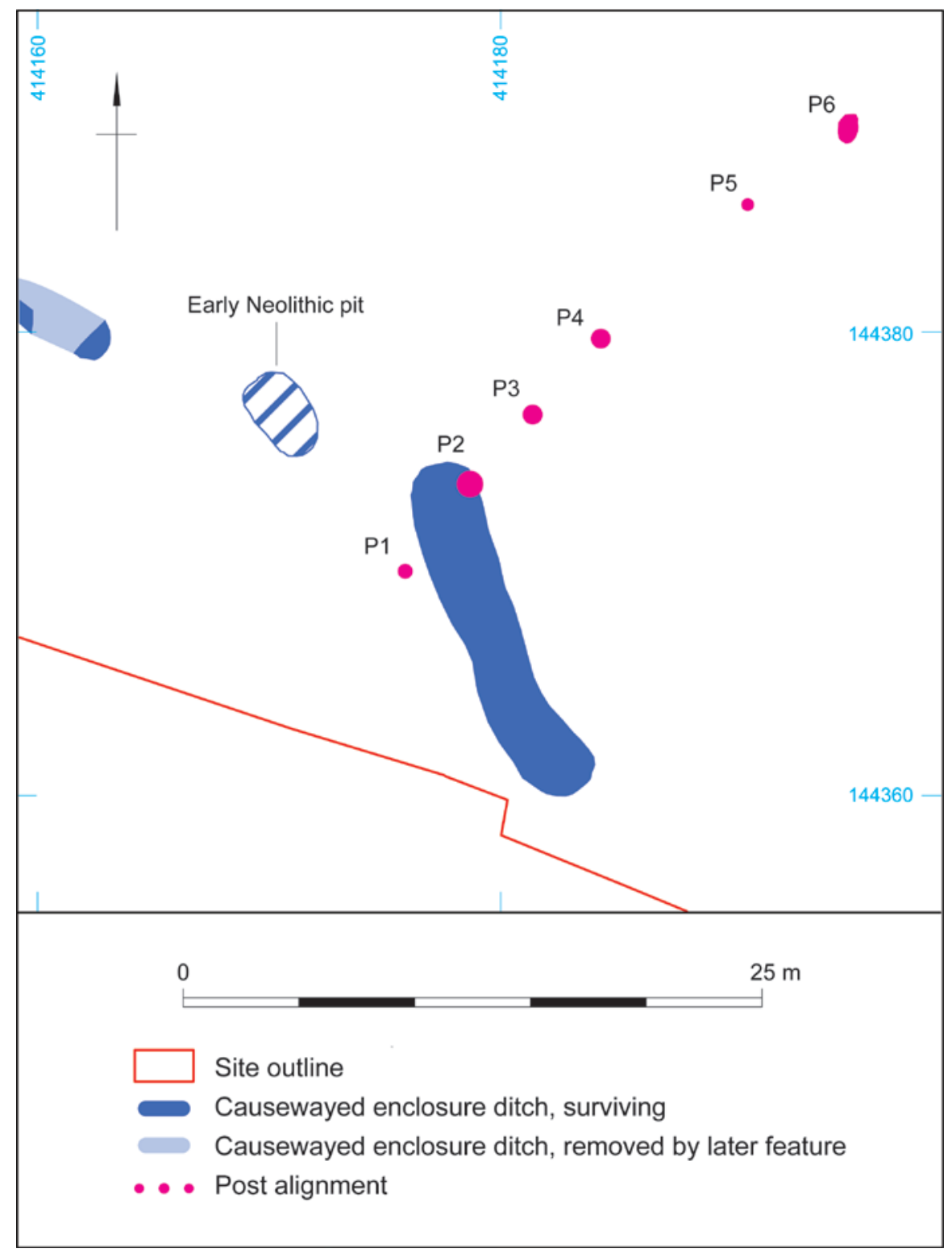

FIGURE 2. The positions of the six postholes.

The dimensions of the postholes set out in Table 1 below are interesting, as they are of reasonably large features which could have held substantial timbers. By comparison, the entrance causeway postholes at Stonehenge (Cleal et al. 1995, 545) generally have a maximum diameter between $0.2 \mathrm{~m}$ and $0.4 \mathrm{~m}$ (only five examples out of 46 being up to $0.6 \mathrm{~m}$ wide). A better comparison might be the smallest postholes at Woodhenge: the 
average diameter of the postholes at Lark Hill is $0.61 \mathrm{~m}$, whereas the smallest postholes at Woodhenge (Ring D) have an average diameter of $0.74 \mathrm{~m}$ (or 29", Cunnington 1929, 10).

TABLE 1. The dimensions of the six postholes at Lark Hill.

\begin{tabular}{|l|l|l|l|}
\hline Posthole & Depth $(\mathbf{m})$ & Max diam $(\mathbf{m})$ & Min diam $(\mathbf{m})$ \\
\hline P1 & 0.60 & 0.62 & 0.35 \\
\hline P2 & 1.08 & 0.90 & 0.43 \\
\hline P3 & 0.74 & 0.66 & 0.65 \\
\hline P4 & 0.84 & 0.70 & 0.62 \\
\hline P5 & 0.50 & 0.46 & 0.26 \\
\hline P6 & 0.80 & 0.90 & 0.75 \\
\hline
\end{tabular}

\section{Field Data and Desktop Analysis}

\section{The Timber Post Alignment: Position and Orientation Data}

On 26th January, 2017, CR, AC and ML, together with Alistair Barclay, at that time of Wessex Archaeology, visited the Lark Hill site while it was still under excavation. Posthole P4 was still visible at this time, although the others had been backfilled. P1-P3 were no longer visible, but the positions of P5 and P6 were marked by metal fenceposts placed on their southeast sides, which gave an approximate indication of the orientation on the ground. As measured by Plastismo prismatic compass, the azimuth along the line of the three postholes $\mathrm{P} 4-\mathrm{P} 6$ was $50^{\circ}$ mag., corresponding to $49^{\circ}$ true (the magnetic declination being $1.1^{\circ} \mathrm{W}$ according to www.ngdc.noaa.gov).

A georeferenced TIFF produced from Wessex Archaeology's excavation survey supplied the OSGB coordinates of the posthole centres, which are listed in Table 2. The position of P4 determined by handheld GPS during the site visit in January 2017 (SU 14183, 44383 ) is within $3.5 \mathrm{~m}$ of the more accurate position quoted in the table and provided a consistency check.

TABLE 2. The OSGB coordinates of the six postholes.

\begin{tabular}{|l|l|l|l|}
\hline P1 & SU & 14175.8 & 44369.7 \\
\hline P2 & SU & 14178.6 & 44373.5 \\
\hline P3 & SU & 14181.3 & 44376.5 \\
\hline P4 & SU & 14184.3 & 44379.8 \\
\hline P5 & SU & 14190.6 & 44385.5 \\
\hline P6 & SU & 14194.9 & 44388.9 \\
\hline
\end{tabular}

As is evident from Figure 2, the line of timber posts was in fact slightly curved. The true azimuths (corrected for grid convergence of $0.16^{\circ}$ ) of the segments between adjacent posts are given in Table 3. The line gradually bends round from azimuth $36.9^{\circ}$ (P1 to P2) to $52.6^{\circ}$ (P5 to P6). 
TABLE 3. The distances and true azimuths between adjacent postholes.

\begin{tabular}{|l|l|l|}
\hline & Dist $(\mathbf{m})$ & True az $\left(^{\circ}\right)$ \\
\hline P1-P2 & 4.7 & 36.9 \\
\hline P2-P3 & 4.0 & 42.4 \\
\hline P3-P4 & 4.4 & 41.8 \\
\hline P4-P5 & 8.6 & 48.0 \\
\hline P5-P6 & 5.4 & 52.6 \\
\hline
\end{tabular}

Postholes P1-P4 are relatively closely spaced, roughly $4 \mathrm{~m}$ apart, with a gap of at least $8 \mathrm{~m}$ to the southwest (this being the distance to the edge of the excavated area, beyond which further postholes may exist). The best-fit azimuth along the line P1 to P4 (determined using the least squares method with perpendicular offsets) is $40.4^{\circ} / 220.4^{\circ}$. The alignment from P4 to P6 has an end-to-end azimuth of $49.8^{\circ} / 229.8^{\circ}$ and a best-fit azimuth for all three postholes of $49.6^{\circ} / 229.6^{\circ}$, which accords with the approximate value of $49^{\circ}$ obtained with the handheld compass (for which an error of $\pm 1^{\circ}$ is to be expected).

\section{The Sightline to the Northeast}

The alignment from P4 to P6 is the closest to the solstitial direction in the northeast. The view in this direction is downhill away from Lark Hill and towards Sidbury Hill, a distinctive feature some $9.5 \mathrm{~km}$ distant that marks the highest point on the northern and northeastern horizon. At the time of our site visit it was only just visible through the gloom (Figure 3). A handheld Suunto clinometer determined the altitude of the top of Sidbury Hill to be approximately $0.5^{\circ}$. The alignment is towards the western shoulder of the hill.

The declinations of the upper limb (first/last gleam), centre and lower limb of the June and December solstitial Sun are given in Table 4.

TABLE 4. The declinations of the upper limb (first/last gleam), centre and lower limb of the June and December solstitial Sun at various dates (after Ruggles 1999, 57). All values are in degrees and quoted to the nearest $0.05^{\circ}$.

\begin{tabular}{|l|l|l|l|l|l|l|}
\hline \multirow{2}{*}{ Epoch } & \multicolumn{3}{|c|}{ June solstice } & \multicolumn{3}{c|}{ December solstice } \\
\cline { 2 - 7 } & Upper & Centre & Lower & Upper & Centre & Lower \\
\hline 3000 BC & +24.3 & +24.05 & +23.8 & -23.8 & -24.05 & -24.3 \\
\hline 2500 BC & +24.25 & +24.0 & +23.75 & -23.75 & -24.0 & -24.25 \\
\hline 2000 BC & +24.2 & +23.95 & +23.7 & -23.7 & -23.95 & -24.2 \\
\hline AD 2000 & +23.7 & +23.45 & +23.2 & -23.2 & -23.45 & -23.7 \\
\hline
\end{tabular}

Digital horizon data has been generated by AS using his Horizon program (agksmith. net/horizon) from the Environment Agency's "LIDAR Composite DTM 2019 - 2m" dataset (Environment Agency 2020), with gaps filled with data from the Ordnance Survey Terrain 50 (2020) dataset (Ordnance Survey 2020). Comparisons have confirmed that for the profiles considered in this paper there is no contribution from the OS $50 \mathrm{~m}$ data. 


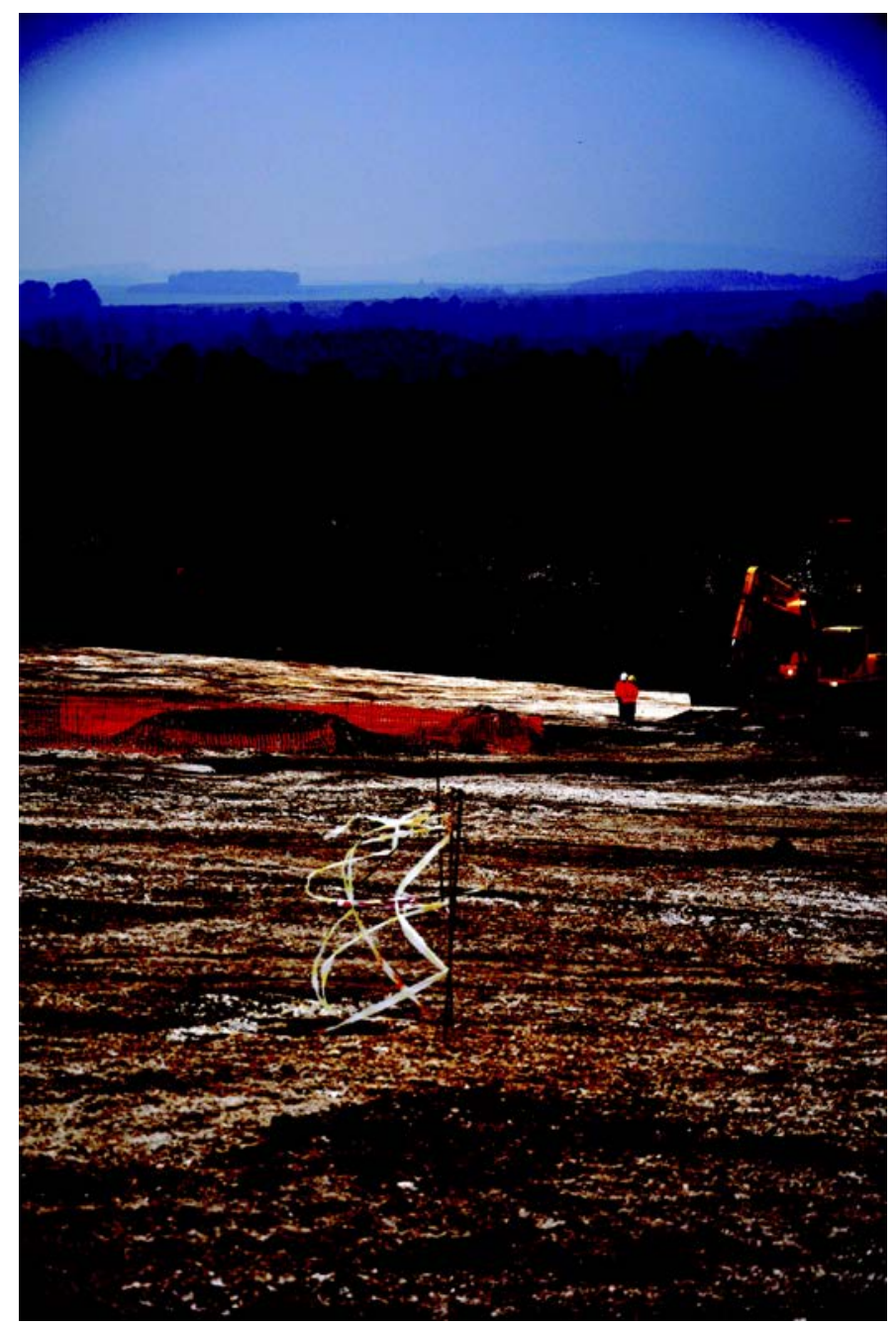

FIGURE 3. Photo taken by CR on 26th January, 2017, showing the positions of postholes P5 and P6 (marked by metal posts to aid visibility) as viewed from P4, strongly enhanced so that Sidbury Hill can just be seen forming the horizon in the far distance (the metal posts were not used for the measurements in this article; see Table 2).

The digital horizon data confirms the horizon altitude in the direction of P4 to P6 to be $0.5^{\circ}$ and, assuming a mean refraction correction, then give the azimuth of the first gleam (upper limb) of the June solstice Sun as $49.1^{\circ}$ (alt $0.5^{\circ}$ ), the centre as $49.7^{\circ}$ (alt $0.55^{\circ}$ ) and the lower limb as $50.1^{\circ}$ (alt $0.55^{\circ}$ ). This is visualised in Figure $4 a$. In the present day the azimuth values have shifted to $50.2^{\circ}, 50.7^{\circ}$ and $51.2^{\circ}$ respectively (Figure $4 \mathrm{~b}$ ).

We conclude that postholes P4-P6 were aligned squarely upon the direction of the rising June solstice Sun at the time of construction, the end-to-end and best-fit azimuths $\left(49.8^{\circ}\right.$ and $49.6^{\circ}$, respectively) coinciding almost exactly with the azimuth of the centre of the rising June solstice Sun in $2400 \mathrm{BC}\left(49.7^{\circ}\right)$. 


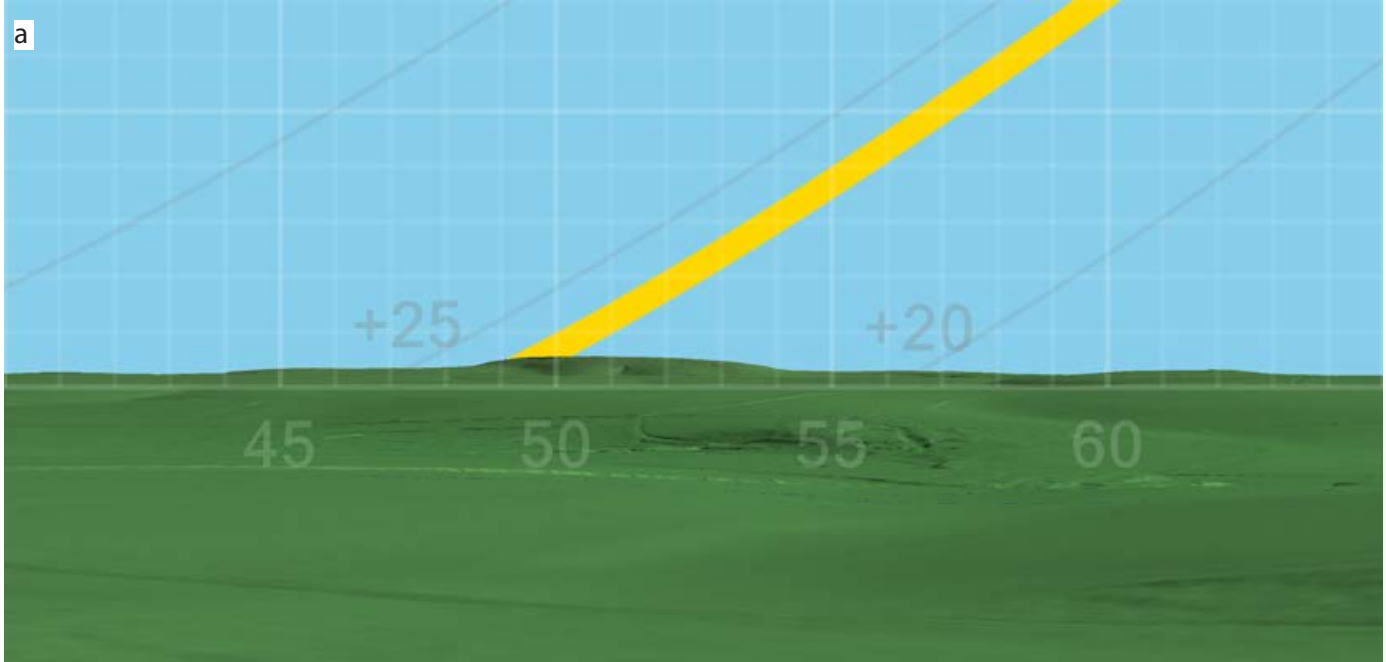

b

FIGURE 4. (a) Horizon profile to the northeast digitally generated from OS $50 \mathrm{~m}$ DTM data, showing the rising path of the June solstice Sun in 2400 BC (yellow band); (b) same, showing the rising path of the June solstice Sun in the present day for comparison.

\section{The Horizon to the Southwest}

In the opposite (southwest) direction along the same posthole alignment the land slopes uphill towards what was once the interior of the causewayed enclosure, now covered in woodland and modern housing. Spot checks using 1:25000 OS contour data indicates that the natural horizon in this direction would have been no greater than $\sim 250 \mathrm{~m}$ even in the absence of vegetation. For a horizon this close the $50 \mathrm{~m}$ terrain data is insufficiently 
accurate to produce a reliable profile, but the $2 \mathrm{~m}$ LiDAR data shows that the natural horizon for an eye-level of $1.5 \mathrm{~m}$ at P6 would have been only some $70-80 \mathrm{~m}$ distant in this general direction, with a segment at a distance of $114 \mathrm{~m}$ visible between azimuth $222.5^{\circ}$ and $225.5^{\circ}$, which creates a very slight bump in the direction of December solstice sunset (Figure 5). It might be tempting to see this as significant, but at this distance changes in even low vegetation would have had a significant impact on the visible horizon, as would changes in the landscape since prehistoric times. We can, however, safely conclude that the horizon altitude in this direction would have been at least $\sim 3.5^{\circ}$.

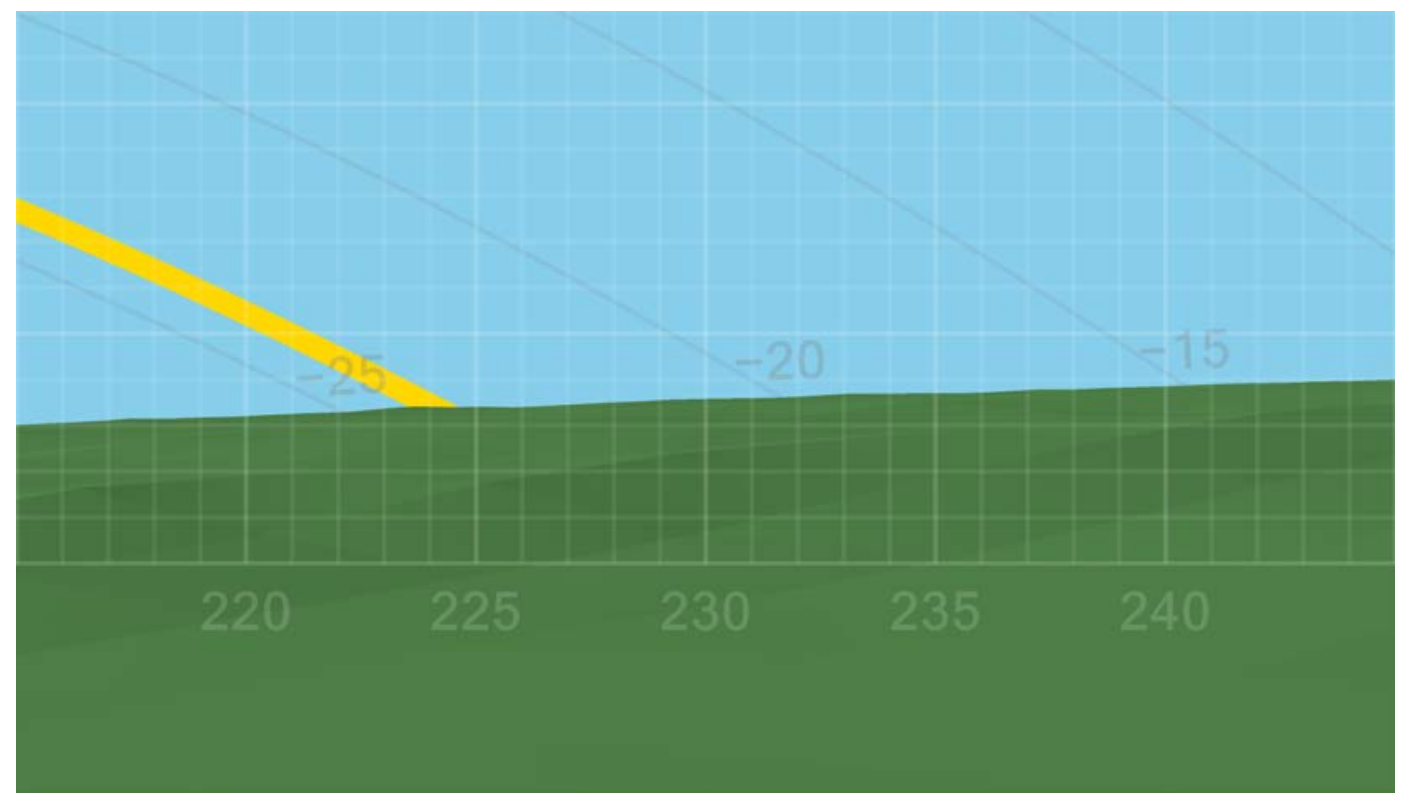

FIGURE 5. Horizon profile to the southwest digitally generated from OS $50 \mathrm{~m}$ DTM data combined with $2 \mathrm{~m}$ LiDAR data, showing the setting path of the December solstice Sun in 2400 BC (yellow band).

What this means is that the December solstice Sun would have been seen to set at an azimuth no greater than $\sim 224^{\circ}$ (as seen in Figure 5), and possibly considerably less if there was significant vegetation. This is several degrees to the left of the alignment along P6 to P4 (end-to-end azimuth $229.8^{\circ}$, best-fit azimuth $229.6^{\circ}$ ), but compares better with the direction along the line from P4 to P1 (end-to-end azimuth $220.2^{\circ}$; best-fit azimuth $220.4^{\circ}$ ) and indeed of the six-post row as a whole (end-to-end azimuth $225.1^{\circ}$; best-fit azimuth $\left.225.3^{\circ}\right)$.

\section{Conclusions of the analysis}

Posts P4-P6 were, unequivocably, accurately aligned upon the June solstice Sun rising over the prominent feature on a distant skyline (Sidbury Hill, $9.5 \mathrm{~km}$ ) at the time of construction. 
While it may be tempting to suggest that either posts P1-P4 or the six-post alignment as a whole might have been broadly aligned in the opposite direction (P6 to P4 to P1) upon December solstice sunset, the extreme proximity of the horizon means not only that the data is uncertain within wide bounds, but also that any alignment in this direction would have been difficult to achieve in practice, given that it would have been significantly affected even by low vegetation. We can, however, say for certain that (1) there could have been no distant sightline in the southwest direction and (2) the higher horizon altitude in the southwest direction effectively rules out a "two-way" solstitial alignment along P4-P6.

\section{Data Selection Issues}

The selection of alignment data is always a critical consideration in archaeoastronomy and it is important to be aware of the data selection issues in this case. The most obvious is that the line of six posts is in fact slightly curved and only the northeasternmost three are accurately aligned upon June solstice sunrise. A curved line contains many potential alignments which, on the face of it, increases the likelihood that the solstitial one is purely fortuitous. On the other hand, the archaeological evidence is unequivocal that the line did not continue further in the northeasterly direction, which means that these three posts were definitely the last in the line, with an unobstructed view for sighting the Sun. This argument continues to hold if the row was originally longer to the southwest, and the curve continued in that direction, i.e. within the interior of the earlier causewayed enclosure.

A further issue is that the line of postholes at Lark Hill is one of at least three similar short rows of postholes located within the excavated areas of the Larkhill housing development site, and the others are not solstitially aligned. Given the extent of the excavated area and the complete lack of any other surviving evidence of postholes, we can say with near certainty that these short lines of posts did not form part of any sort of continuous palisade: indeed, it is not even clear whether they were broadly contemporary. Nonetheless, the existence of these other non-solstitial lines of posts might be seen as increasing the likelihood that the solstitial alignment at Lark Hill is merely fortuitous.

The response to this is an archaeological one. What distinguishes the Lark Hill posts is that they are clearly related to a significant archaeological feature: the causewayed enclosure. The nearest of the other lines of posts could conceivably relate to a nearby Middle Bronze Age enclosure, but the others have no such association. What these other short rows of postholes do have in common, however, is that they appear to be related to two large natural sinkholes forming part of a sinuous line of "solution hollows" running down one side of the dry valley (see below). Each posthole row ran in the general direction of this line, at a similar distance from the sinkhole concerned, on its southeastern side.

\section{Discussion}

The astronomical importance of the Stonehenge landscape has been recognised by UNESCO since 2008 as part of the "Outstanding Universal Value" of the "Stonehenge, 
Avebury and Associated Sites" World Heritage Site (whc.unesco.org/en/list/373), as set out in its Statement of Significance (UNESCO 2008). Six solstitial sightlines within (and extending beyond) the Stonehenge WHS boundary have been noted in the second ICOMOS Thematic Study on astronomical heritage (Chadburn and Ruggles 2017). These are summarised in Table 5.

TABLE 5. The six solstitial sightlines within the Stonehenge WHS (details from Ruggles 2006 and Chadburn and Ruggles 2017, slightly modified following analysis using the new $2 \mathrm{~m}$ LiDAR data).

\begin{tabular}{|c|c|c|c|c|c|c|}
\hline Solstice & $\begin{array}{l}\text { Site and features indicating the } \\
\text { sightline }\end{array}$ & End point/ landscape target & $\begin{array}{l}\text { Dist } \\
(\mathbf{k m})\end{array}$ & $\begin{array}{l}\text { Mean } \\
\text { az }\left(^{\circ}\right)\end{array}$ & $\begin{array}{l}\text { Alt } \\
\left({ }^{\circ}\right) \\
\end{array}$ & $\operatorname{Dec}\left({ }^{\circ}\right)$ \\
\hline \multirow[t]{2}{*}{ Dec, set } & Stonehenge complex: symmetry axis & $\begin{array}{l}\text { Unnamed hill near Druid's } \\
\text { Lodge at SU } 089394\end{array}$ & 4.4 & 229.9 & 0.5 & -23.8 \\
\hline & Woodhenge: symmetry axis & King Barrow Ridge & 2.1 & 230.5 & 0.3 & -23.7 \\
\hline \multirow[t]{2}{*}{ June, rise } & Stonehenge complex: symmetry axis & $\begin{array}{l}\text { Slope south of The Packway } \\
\text { Road }\end{array}$ & 3.0 & 49.9 & 0.6 & +23.9 \\
\hline & Woodhenge: symmetry axis & Brigmerston Field & 4.1 & 50.5 & 0.5 & +23.5 \\
\hline Dec, rise & $\begin{array}{l}\text { Durrington Walls Henge: South Circle } \\
\text { symmetry axis }\end{array}$ & Boscombe Down West & 4.2 & 130.4 & 0.5 & -24.0 \\
\hline June, set & Durrington Walls Henge: avenue & $\begin{array}{l}\text { Slope to the NW of the NW } \\
\text { bank of henge }\end{array}$ & 0.7 & 306.7 & $\sim 4.0$ & $\sim+25.2$ \\
\hline
\end{tabular}

Note: The "Stonehenge complex" includes the sarsen stone horseshoe, Station Stone rectangle and the closest segment of the Avenue, all aligned to within about $0.3^{\circ}$ along the same axis (Ruggles 2006, table 3).

The accurate solstitial alignment, in at least one direction, of the main axes of not one but three associated major Late Neolithic (LN) monuments and monument complexes (Stonehenge complex, Woodhenge, and Durrington Walls Henge) provides convincing evidence of a consistent local practice. This contrasts with the far less precise solar-related orientations (typically combined with other factors) that are found among groups of later prehistoric temples and tombs widely across western and Mediterranean Europe (Hoskin 2001), and indeed among EN long barrows in the Wessex chalklands. Precise solstitial sightlines accurate to within $0.5^{\circ}$, or 1 solar diameter, evidently formed an integral part of the Stonehenge landscape in the mid-third millennium BC. This conclusion has achieved scholarly consensus precisely because the sightlines are very obvious in the design of the monuments and are repeated, and so are unlikely to have arisen fortuitously.

The new evidence presented here raises the possibility that a contemporary alignment of timber posts built across the edge of the earlier Lark Hill Enclosure may have been of significance within this tradition, albeit of a less permanent or monumental nature. That said, these postholes held substantial posts rather than, for example, the small stakes in the entrance causeway to the Stonehenge enclosure (Cleal et al. 1995, 140-146) that generated so much debate over their possible lunar significance during the 1970s and 1980s (see Ruggles 1997, 214-217). The Lark Hill alignment is definitely oriented 
northeast, towards the distant skyline feature of Sidbury Hill and June solstice sunrise, but is highly unlikely to have also been deliberately oriented in the opposite direction, where the land ran uphill and there was no distant view.

The selection issues discussed above raise the question of whether the Lark Hill postholes were placed at what was already seen as an auspicious spot, which could explain why these particular posts might have been deliberately configured so as to incorporate the solstitial alignment.

A possible answer derives from the fact that the entrance to Lark Hill Enclosure is situated at the head of a dry valley leading down to a bend in the River Avon, which heads off in the broad direction of June solstice sunrise. Added to this, a line of very large natural sinkholes (solution hollows), which would certainly have been visible in both the EN and LN landscape and may have been artificially elaborated, leads off down the valley in the same general direction. A shallow EN pit in the entrance of the enclosure, which is broadly aligned with the sinkholes, seems to confirm that the sinkholes were seen as significant and could be interpreted as an attempt to incorporate these natural features into the constructed monument. (The fact that the relationship between the Lark Hill postholes and the entrance pit is similar to that between the other short rows of postholes and some of the sinkholes, as mentioned above, reinforces this impression.) If so, then a broad cognitive connection between monument, landscape (specifically, a bend in the River Avon) and skyscape (specifically, June solstice sunrise) that was established in the EN might have carried through to the $L N$, a millennium later, where it becomes evident again in the location and orientation both of Durrington Walls Henge (which is also at the head of a dry valley leading off in a different solstitial direction down to a bend in the Avon) and also of Stonehenge itself, whose Avenue also leads to another major meander in the river.

If this entrance to the Lark Hill Enclosure was already significant in EN times, and the broad connection of this location to the June solstice sunrise was long established, then it makes more sense why the post alignment might well have been constructed to mark it more precisely in the mid-third millennium BC, forming an intentional part of the tradition of precise solstitial alignments that emerged in this area around this time in the LN.

The evidence remains far from conclusive, but the discovery of the Lark Hill postholes and their alignment upon Sidbury Hill and June solstice sunrise does raise the intriguing possibility that here, just outside the WHS boundary, lies a significant solstitial sightline that should not only be added to the tally now known to have been monumentalised within the LN landscape around Stonehenge, but may well contribute to the story of how and why they developed over time.

\section{References}

Chadburn, A. and C. L. N. Ruggles, 2017. "Stonehenge World Heritage Property, UK: IAU Extended Case Study". In Heritage Sites of Astronomy and Archaeoastronomy in the Context of the UNESCO World Heritage Convention: A Thematic Study, vol. 2, by C. L. N. Ruggles and M. Cotte, with contributions by others, 41-62. Paris: ICOMOS [online]. Accessed February, 2020, https://www3.astronomicalheritage.net/ images/astronomicalheritage.net/media/ahp_entities/entity000049/TS2-04-Stonehenge.pdf

Cleal, R. M. J., K. E. Walker and R. Montague, 1995. Stonehenge in its Landscape: Twentieth-Century Excavations. London: English Heritage. 
Cunnington, M. E., 1929. Woodhenge: A Description of the Site as Revealed by Excavations. Devizes: George Simpson \& Co.

Environment Agency, 2020. "LIDAR Composite DTM 2019 - 2m” [online]. Accessed July 2020, data.gov.uk/ dataset/67639c1b-ac0e-492a-abba-02ed436f826f/lidar-composite-dtm-2019-2m

Hoskin, M. A., 2001. Tombs, Temples and their Orientations. Bognor Regis: Ocarina Books.

Leivers, M., 2017. "Robin Hood's Other Ball? A Newly-Discovered Causewayed Enclosure at Larkhill, Wiltshire". PAST 85: 12-13 [online]. Accessed July 2020, www.prehistoricsociety.org/publications/publication/past_85_april_2017/

Leivers, M., 2021. "The Army Basing Programme, Stonehenge and the Emergence of the Sacred Landscape of Wessex". Internet Archaeology 56, https://doi.org/10.11141/ia.56.2

Ordnance Survey, 2020. "OS Terrain 50" [online]. Accessed July 2020, www.ordnancesurvey.co.uk/businessgovernment/products/terrain-50

Ruggles, C. L. N., 1997. "Astronomy and Stonehenge". In Science and Stonehenge, edited by B. W. Cunliffe and A. C. Renfrew, 203-229. London: British Academy/Oxford University Press.

Ruggles, C. L. N., 1999. Astronomy in Prehistoric Britain and Ireland. New Haven, CT: Yale University Press.

Ruggles, C. L. N., 2006. "Interpreting Solstitial Alignments in Late Neolithic Wessex". Archaeoastronomy: The Journal of Astronomy in Culture 20: 1-27.

UNESCO, 2008. "Decision : 32 COM 8B.93" [online]. Accessed August 2020, whc.unesco.org/en/decisions/1539 